\title{
STEP-BY-STEP PROCESS
}

\section{POPULATION PRE-ASSESSMENT - One time}

1. Define your population using previous data (any time frame). Input your data in the "Population data" tab in the template provided in $\$ 4$.

2. Calculate TWSA using the regression equations presented on Table 1 and Equation 1. Use the script on \$3 for the calculations.

3. Identify the medTWSAind and medBWDind.

\section{ARRIVALS PRIORIZATION - Daily}

1. Calculate PPP score to prioritize daily arrivals: Input the "Arrivals data" in the template provided in \$4.

2. Calculate TWSA as described for the Population preassessment, if not available already.

3. Use Equation 2 (included in the script on \$3) to calculate the PPP score.

\section{POPULATION PATTERNS - Retroactively}

Calculate Cumulative PPP score on specific locations and/or vessel type by summing individual PPP scores. 